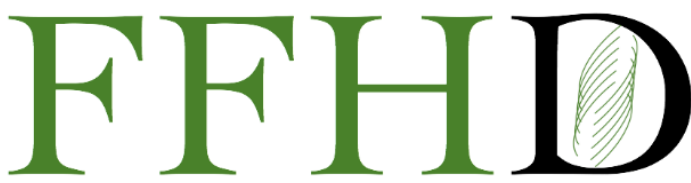

Functional Foods in Health and Disease

\title{
Effect of cassava on proximate composition, insulin index, glycemic profile, load, and index in healthy individuals: a cross-sectional study
}

\author{
Blessing Myke-Mbata*, Simeon Adelani Adebisi, Basil Bruno, Terry Terfa Gbaa
}

Department of Chemical Pathology, Benue State University Makurdi, Makurdi, Nigeria

*Corresponding Author: Blessing Myke-Mbata, MBBS, FMCPath, Department of Chemical Pathology, Benue State University Makurdi, Nigeria

Submission Date: December 22 ${ }^{\text {nd }}, 2020$; Acceptance Date: January $14^{\text {th }}, 2021$; Publication Date: January $26^{\text {th }}$, 2021

Please cite this article as: Myke-Mbata B., Adebisi S., Bruno B., Gbaa T. Effect of cassava on proximate composition, insulin index, glyceamic profile, load, and index in healthy individuals: a cross-sectional study. Functional Foods in Health and Disease 2021. 11(1): 1-10. https://www.doi.org/10.31989/ffhd.v11i1.772

ABSTRACT
Background: The major
challenge in Africa is the
growing prevalence of
metabolic syndrome which
has been attributed to
changing lifestyles in developing countries. The impact of the commonly available staple starchy food; eaten
in this environment may also be a factor contributing to growing concerns of metabolic syndrome. Hence,
the need to assess the affordable staple starchy foods. Cassava is the most consumed staple starchy food in
our environment; therefore, our study evaluated its impact on glycaemic and insulin response in consumers.
Aim: To determine Insulin Index (II), glycaemic profile (GP), glycaemic load (GL) and Glycaemic Index (GI),
incremental glucose peak value (IGPV), and glycaemic profile index (GPI) of cassava food meals.
Methods: Participants ingested three cassava processed products (cassava dough [fufu], chips [Abacha], and
flakes [garri] (the equivalent of $50 \mathrm{~g}$ glucose) and $50 \mathrm{~g}$ of reference meal (glucose solution). Fasting and post-
prandial samples were taken for blood glucose and insulin however sample for glucose was taken at intervals
of 30 mins to a maximum of 180 mins and 120 mins for insulin, respectively.


Result: The GI for cassava dough, flakes and chips were 93.26; 95.92 and 91.94, respectively. Their glycaemic load was 46.62; 47.96 and 45.97, respectively. The glycaemic profile index was 37.34; 41.41 and 46.19, respectively. In addition, the insulin index was 55.83; 69.36 and 97.02 . The proximate analysis showed protein, moisture, fibre, fat, ash, and carbohydrate content as follows the cassava (\%) (crude form) 1.075\%; 72.00\%; 0.80\%; 0.58\%; 0.35\%; 25.07\%, Chips 1.44\%; 59.13\%; 0.73\%; 1.71\%; 36.83\%, flakes 1.82\%; 67.36\%; $0.15 \% ; 0.91 \% ; 0.25 \% ; 39.64 \%$ and dough $1.56 \% ; 67.51 \% ; 0.21 \% ; 0.52 \% ; 0.20 \% ; 30.22 \%$ respectively.

Conclusion: II, GP, GL, and GI of cassava dough (fufu), cassava flakes(garri)and cassava chips (Abacha) were found to be high. Unregulated dietary intake in adults may lead to metabolic diseases.

Keywords: Glycaemic index, Glycaemic load, Glycaemic profile, Cassava, Makurdi

CFFC 2021. This is an Open Access article distributed under the terms of the Creative Commons Attribution 4.0 License (http://creativecommons.org/licenses/by/4.0)

\section{BACKGROUND}

There has been a surge in the prevalence of metabolic syndrome in developing country especially in the urban areas which are dominated by dwellers with a sedentary lifestyle. Diet and activity play a major role in determining the risk of metabolic syndrome in addition to underlying genetics. Cassava meals are foods commonly eaten in Africa. Most Africans consume it daily at least once a day in various forms using various processing methods. These processing methods are meant to remove cyanide from cassava foods as well as provide food variety for consumers. Cassava dough, cassava flakes, and cassava chips are common products of cassava commonly consumed in Nigeria. There has been a huge controversy over the health impact of continuous cassava consumption on the health of Africans with the changing lifestyle. Therefore, this study examined the glycaemic response to cassava consumption. Knowledge of insulin index (II), glycaemic profile (GP), and glycaemic load (GL), an index of cassava meal will aid the informed choice of source of energy and thus help the adult individuals to improve their life expectancy and quality of life.

Glycaemic Index: The glycaemic index is a measure of the hyperglycaemic power of food relative to a standard food challenge of 50 grams of glucose in $300 \mathrm{ml}$ of water. The $\mathrm{Gl}$ is defined as the incremental area under the blood glucose response curve of a 50-gram carbohydrate portion of a test food expressed as a percentage of the response to the same amount of carbohydrate from a standard food taken by the same subject. [1] The GI compares the potential of foods containing the same amount of carbohydrates to raise blood glucose.

Glycaemic Load: The GL of food, on the other hand, is a number that estimates how much a food will raise a person's blood glucose level after its consumption. One unit of $\mathrm{GL}$ approximates the effect of consuming one gram of glucose [1]. Since the Gl does not consider the number of carbohydrates in a food; glycaemic load may be a better indicator of how a carbohydrate food will affect blood glucose.

Glycaemic Profile: Additionally, The GP provides a more accurate picture of the blood glucose response because it takes the curve's appearance into account. It is a description of the appearance of the blood glucose response curve. The glycaemic profile is based on the graph of the rise and fall of postprandial blood glucose. The scores of the 
glycaemic profiles show the appearance of the glycaemic curve. The flatter the curve, the better the glycaemic profile and the higher it scores. High glycaemic profile scores indicate that blood glucose rises slowly and evenly after a meal and then drops slowly. Low scores indicate that there were a sudden spike and rebound drops into hypoglycemia.

Insulin Index: The insulin index of food defines the extent blood insulin concentration is elevated during the two hours after its ingestion. An insulin index (II) has been defined as a direct index of the postprandial insulin response to a test food in comparison with an isoenergic portion of a reference food (analogous to the Glycaemic Index, either glucose or white bread) while GI represents a comparison of portions with equal digestible carbohydrate content (typically $50 \mathrm{~g}$ ) and the GL represent portions of typical serving size for various foods, the Insulin Index can be more useful than either the Glycaemic Index or the Glycaemic Load because certain foods (e.g., lean meats and proteins) cause an insulin response despite there being no carbohydrates present, and some foods cause a disproportionate insulin response.

High dietary GL has been associated with an increased risk of developing type 2 diabetes mellitus (DM) in several large prospective studies. Likewise, high dietary glycaemic loads have been associated with increased serum levels of High sensitivity C-reactive protein (hsCRP), a marker of systemic inflammation that is also a sensitive predictor of cardiovascular disease risk. [2] In addition to increased blood glucose and insulin concentrations, high dietary glycaemic loads are associated with increased serum triglyceride concentrations and decreased High-Density Lipoprotein cholesterol (HDLC) concentrations which are risk factors for cardiovascular disease. $[3,4]$ Therefore, this study carried out the proximate analysis of different cassava meals and determined their effect on II, GP, GL, and GI of healthy consumers to aid individuals, health workers, nutritionists, and dietitians to make informed choices.

\section{MATERIALS AND METHODS}

The study design was a cross-sectional study. Systematic sampling technique was used in participant selection. The 65 healthy participants were recruited from the staff of Benue State University Teaching Hospital whose ages were between (40-60 years) [5]. Those with a history of diabetes mellitus, hypertension or any other chronic illness were excluded from the study.

Ethical Consideration: Ethical approval was obtained from the Benue State University Teaching Hospital Makurdi Informed written consent was obtained from the participants for the study. Confidentiality was ensured throughout the study by using number codes which were allotted to each participant and result obtained from the blood analysis for the study was kept confidential in such a manner that no person can use the information to trace or know the patient.

Food Preparation and Processing: Cassava tubers were obtained from a particular farmyard at Adeke, Naka Road, Makurdi. Preparation of Cassava Flakes (Garri) Cassava was peeled, washed, and grated; the grated mash was put in jute sacks and pressed using screw press and it was left for a day to dry and ferment, then the dehydrated mash was sieved and fried to produce garri. The entire period of processing was 2 days.

Preparation of Cassava Paste (Fufu): Peeled cassava was washed and cut into thick chunks and soaked in water for 3 days, during this period, the cassava was fermented and softened, the cassava was sieved in clean water and the starchy particles that pass through the sieve could settle for about 3 to 4 hours. The water was then decanted while the sediment was packed into a cloth bag, tied, squeezed, and subjected to a manual pressure to expel excess water. Cassava 
extract was rolled into balls and cooked in boiling water for about 30 to 40 minutes. The cassava was then pounded with mortar and pestle to produce a white paste.

Preparation of Cassava Chips (Abacha): Peeled cassava was cut and sliced with a local grater producing cassava chips that are about $2 \mathrm{~mm}$ in thickness and $1 \mathrm{~cm}$ in length, then soaked and washed daily for 3 days. This was fried with $2 \mathrm{ml}$ of palm oil, $1 \mathrm{~g}$ of crayfish, and a pinch of salt.

Preparation of Reference Meal (glucose solution): Anhydrous glucose of analytic grade (50 g) was dissolved in $300 \mathrm{ml}$ of potable water and drank within 5 mins as recommended by the World Health Organization/Food and Agriculture Organization (WHO/FAO) expert consultation panel. [6]

Procedure: Each subject ingested three cassava processed products (cassava dough, chips, and flakes, the equivalent of $50 \mathrm{~g}$ glucose) and a reference meal which is $50 \mathrm{~g}$ of anhydrous glucose dissolved in $300 \mathrm{mls}$ of water. One meal-type was served to all participants in one session as follows day 1 (reference meal), day 2(cassava flakes), day 3(cassava dough), day 4(cassava chips) (Each test meal was portioned once with each serving containing $50 \mathrm{~g}$ of digestible carbohydrate with $5 \mathrm{mls}$ of vegetable soup as served in this locality to enable participants to swallow the foods). The weighed food intake equivalent to $50 \mathrm{~g}$ of glucose given to the participants of the study for cassava flakes, cassava dough, and cassava chips respectively were $190 \mathrm{~g}, 133.6 \mathrm{~g}$ and $133.6 \mathrm{~g}$, respectively. The three-different meals from cassava were obtained from the processing methods described above and were ingested by the participants after determining their serving size portions containing $50 \mathrm{~g}$ digestible carbohydrates using standard methods of food analysis and a table of food composition for use in Africa [7]. Blood samples were drawn for fasting and postprandial plasma glucose at $0,30,60,90,120,180$ minutes respectively after cassava meal intake while that for insulin was drawn at Omins, 30, 60, 90,120 only. The method of Rasmussen et al., [8] was used to determine the GI of each meal in both healthy and diabetic subjects.

Determination of Glycaemic Index, Insulin Index, Glycaemic Profile and Load Determination of Glycaemic Index: The area under the curve was determined using the trapezoid method of different time intervals, A plot of concentration against time was used for the calculation, AUC, = Conc $_{2}+$ Conc $_{1} 2 \times\left(t_{2}-t_{1}\right)[9,10]$.

Determination of Glycaemic Index: The area under the curve for each sample cassava dough, flakes, and chips menu was divided by the sum of area under curve for standard glucose and multiplied by 100. The value obtained is the Glycaemic Index and the formula used is given below:

Glycaemic Index (GI) = AUC of test meal/AUC of reference meal (glucose solution)*100. [11].

Determination of Glycaemic Profile: The course of glycaemia was analyzed by calculating a glycaemic profile (GP); the time ( $\mathrm{min}$ ) during which the blood glucose was above fasting concentration was divided with the incremental glycaemic peak value for each subject and test meal. In the cases where the blood glucose concentration remained above fasting for the entire $180 \mathrm{~min}$, the duration value was set to $180 \mathrm{~min}$. A GP index was calculated from the GP by using $50 \mathrm{~g}$ of glucose as a reference meal (GP Index = 100) [12].

Determination of Glycaemic Load (GL): In calculating food's GL, its GI was multiplied by the number of carbohydrate grams in a serving, and then divide by 100. [13] A low GL was taken to be between 1 and 10; a moderate GL was taken to be within the range of 11 to 19 , and a high GL was taken to be 20 or higher.

Glycaemic Load (GL) = Glycaemic Index $x$ Carbohydrate in grams in a serving portion 
Determination of Insulin Index: Insulin Index was determined in the same way as GI food to categorize carbohydrate rich foods based on equal quantities of foods that elicit similar insulin responses [12] The area under the curve was determined using the trapezoid method of different time intervals. $[9,10]$ A plot of concentration against time was used for the calculation,

$$
A U C_{1}=\left(\text { Conc }_{2}+\text { Conc }_{1}\right) 2 \times\left(t_{2}-t_{1}\right) .
$$

The Insulin index was calculated using the following formulae:

Insulin Index= AUC of test meal /AUC of an equal weight of reference glucose $x$ Amount of food

\section{Food Proximate Nutrient Composition and Calorie}

Analysis: Portions of each test food containing 50g digestible carbohydrates analysed for their nutrient (proximate) composition i.e., the carbohydrates, protein, fat, fiber, ash, and moisture content. The methodology of laboratory determination of the proximate nutrient composition and the energy according to the Standard Official Methods of Food Analysis of The Association of Official Analytical Chemist and Principles and Techniques in Food Analysis was used in this study [13]. The proximate nutrient composition was done thrice, and the average was taken.
Data Analysis: Data analysis was done using the Statistical Package for Social Sciences (SPSS) and Microsoft excel packages. Proximate composition, Glycaemic Index (GI), Insulin Index (II), Glycaemic Load (GL), Glycaemic Profile (GP) and Glycaemic Profile Index (GPI) were compared across the cassava products studied. A p-value less than 0.05 is taken as significant.

\section{RESULT}

Proximate analysis of cassava tuber (raw form) and cassava meals eaten by the participants were shown in table 1. Cassava chips (Abacha) was found to have significantly $(p<0.05)$ increased fat and carbohydrate than the cassava tuber (crude form) while its fiber content was found to be significantly $(p<0.05)$ lower than that of the crude form. However, it has significantly abundant fibre, fat, and carbohydrate content than cassava dough and cassava flakes. Cassava flakes constitute more protein than all the crude form and cassava meals studied. More so, it contains more carbohydrate than cassava dough. Lastly, Cassava dough has significantly less $(p<0.05)$ fibre content than the crude form of cassava, cassava flakes and cassava chips. It also has significantly $(p<0.05)$ decreased carbohydrate content than cassava chips and flakes.

Table 1. Proximate Analysis of Food Samples (\%)

\begin{tabular}{lcccccc}
\hline Sample & Protein & Moisture & Fibre & Fat & Ash & Carbohydrate \\
$\begin{array}{l}\text { Cassava tuber } \\
\text { (Crude form) }\end{array}$ & $1.07 \pm 0.02^{\mathrm{d}}$ & $72.00 \pm 0.21^{\mathrm{d}}$ & $0.80 \pm 0.07^{\mathrm{d}}$ & $0.58 \pm 0.03^{\mathrm{d}}$ & $0.35 \pm 0.02^{\mathrm{d}}$ & $25.07 \pm 0.03^{\mathrm{cd}}$ \\
\hline Cassava chips & $1.44 \pm 0.04$ & $59.13 \pm 0.15^{\mathrm{ac}}$ & $0.73 \pm 0.015^{\mathrm{N}}$ & $1.71 \pm 0.02^{\mathrm{ac}}$ & $0.33 \pm 0.02$ & $36.83 \pm 0.08^{\mathrm{ac}}$ \\
\hline Cassava flakes & $1.82 \pm 0.10^{\mathrm{ab}}$ & $67.36 \pm 0.09^{\mathrm{ab}}$ & $0.15 \pm 0.02^{\mathrm{a}}$ & $0.91 \pm 0.09$ & $0.25 \pm 0.05$ & $39.64 \pm 0.03^{\mathrm{ac}}$ \\
& $\mathrm{c}$ & & & & & \\
\hline & & & & & & \\
\hline Cassava dough & $1.56 \pm 0.021^{\mathrm{d}}$ & $67.51 \pm 0.19^{\mathrm{b}}$ & $0.21 \pm 0.02^{\mathrm{ab}}$ & $0.52 \pm 0.02^{\mathrm{b}}$ & $0.20 \pm 0.01^{\mathrm{a}}$ & $30.22 \pm 0.021^{\mathrm{abd}}$
\end{tabular}

$a=$ significant $(p<0.05)$ on comparing to crude form of cassava, $b=$ significant $(p<0.05)$ on comparing to cassava chips $\mathrm{c}=$ significant $(\mathrm{p}<0.05)$ on comparing to cassava dough $d=$ significant $(p<0.05)$ on comparing to cassava flakes 
Table 2. Characteristics of subjects studied (Mean \pm SD)

\begin{tabular}{lll}
\hline Variables & $\mathbf{( N = 6 5 )}$ & P-Value \\
\hline AGE (years) & $49.00 \pm 9.93$ & 0.924 \\
\hline WEIGHT (kg) & $64.50 \pm 4.20$ & 0.750 \\
\hline HEIGHT (cm) & $1.59 \pm 0.037$ & 0.534 \\
\hline BMI & $25.22 \pm 1.10$ & 0.731
\end{tabular}

Table 2 described the characteristics of subjects studied which includes age, weight, height, and Body Mass Index (BMI) of participants of the study.

Table 3. Average Fasting Plasma Glucose (AFPG), Average Fasting Insulin (AFI), Quantitative Insulin Sensitivity Check Index (QUICKI), Homeostatic Model Assessment for Insulin Resistance (HOMA-IR) (Mean \pm SD)

\begin{tabular}{ll}
\hline PARAMETERS & MEAN $\pm S D$ \\
\hline AFBG & $4.01 \pm 0.51$ \\
\hline AFI & $7.08 \pm 2.58$ \\
\hline QUICKI & $0.37 \pm 0.03$ \\
\hline HOMA-IR & $1.28 \pm 0.51$
\end{tabular}

Table 3 indicates the average fasting glucose, average fasting insulin, quantitative insulin sensitivity check index (QUICKI), homeostatic model of assessment for insulin resistance (HOMA-IR) Table 4 indicates the glucose concentration values ( $\mathrm{mmol} / \mathrm{l}$ ) for participants after intake of reference meal, cassava dough (fufu), cassava flakes(garri), cassava flakes (Abacha) at $0,30,60,90,120,150$ and 180 mins. Values are expressed as mean \pm SD. *significant at $P<0.05$. ** Significant at $P<0.01$

Table 4. Mean Glucose Concentration values ( $\mathrm{mmol} / \mathrm{L}$ ) after intake of reference glucose, cassava dough (Fufu), cassava flakes (Garri), cassava chips (Abacha) (Mean \pm SD)

\begin{tabular}{ccccc}
\hline Time (Mins) & Reference Meal (Glucose) & Cassava Dough (Fufu) & $\begin{array}{l}\text { Cassava Flakes } \\
\text { (Garri) }\end{array}$ & $\begin{array}{c}\text { Cassava } \\
\text { Chips } \\
\text { (Abacha) }\end{array}$ \\
\hline 0 & $(\mathrm{~N}=65)$ & $(\mathrm{N}=65)$ & $(\mathrm{N}=65)$ & $3.61 \pm 0.84$ \\
\hline & $4.38 \pm 0.42$ & $4.07 \pm 0.86$ & $3.98 \pm 0.67$ & $4.02 \pm 0.91$ \\
\hline 30 & $4.65 \pm 1.21$ & & $4.23 \pm 0.68$ & $4.42 \pm 1.14$ \\
\hline 60 & $5.68 \pm 1.05$ & $4.26 \pm 0.89$ & $4.56 \pm 0.73$ & $4.21 \pm 0.81$ \\
\hline 90 & $4.57 \pm 1.02$ & $4.45 \pm 1.05$ & $4.71 \pm 0.85$ & $3.99 \pm 0.58$ \\
\hline 120 & $3.46 \pm 1.30$ & $4.42 \pm 0.97$ & $4.85 \pm 1.02$ & $3.84 \pm 0.46$ \\
\hline 150 & $3.63 \pm 0.94$ & $4.39 \pm 0.99$ & $4.77 \pm 1.08$ & $3.67 \pm 0.27$
\end{tabular}

Table 4 indicates the glucose concentration values ( $\mathrm{mmol} / \mathrm{l}$ ) after intake of reference meal, cassava dough (fufu), cassava flakes(garri), cassava flakes (Abacha) at 0,30,60,90,120,150 and 180 mins. 


\section{GLYCAEMIC RESPONSE PATTERN}

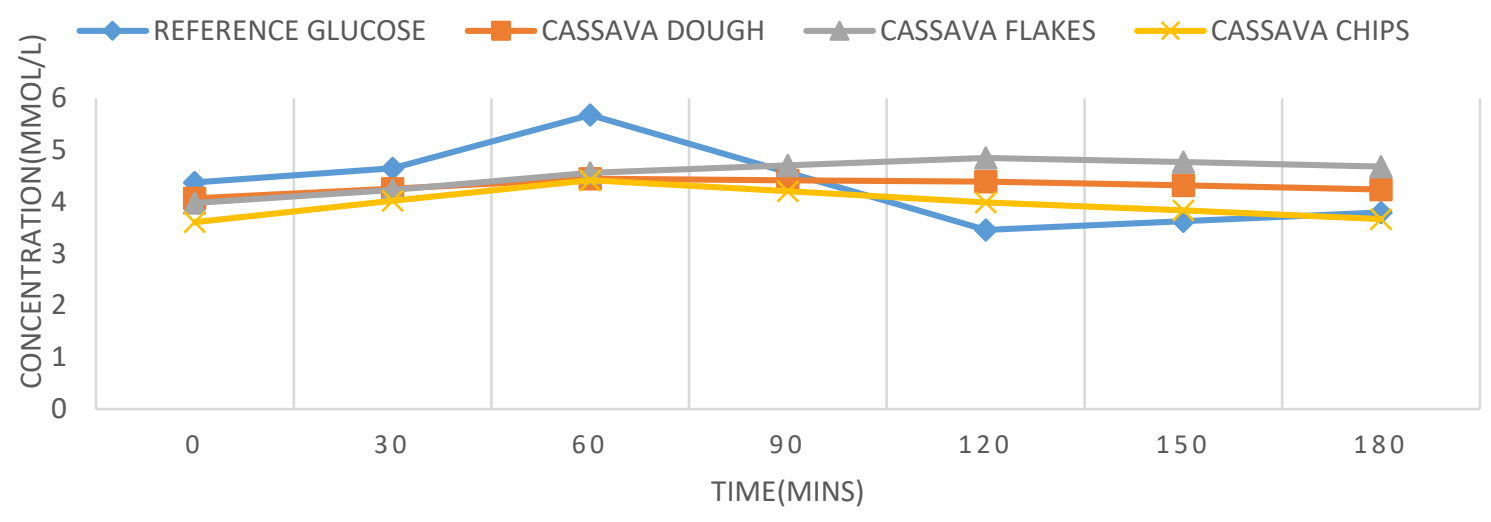

Figure 1: Post-Prandial glycaemic response pattern

Figure 1 shows the post-prandial glycaemic response for the participants, the reference glucose meal remained above all the food meals studied and reduced at 120 minutes below fasting value while other cassava food meals remained above the fasting blood glucose concentration even at $180 \mathrm{mins}$ except cassava chips whose mean blood concentration reduced to the fasting level at 180 minutes.

Table 5. Mean Insulin Concentration values ( $\mu \mathrm{lu} / \mathrm{Ml}$ ) after intake of reference glucose, cassava dough (Fufu), cassava flakes (Garri), cassava chips (Abacha) (Mean \pm SD)

\begin{tabular}{|c|c|c|c|c|}
\hline $\begin{array}{l}\text { Time } \\
\text { (Mins) }\end{array}$ & $\begin{array}{l}\text { Reference Meal } \\
\text { (Glucose) }\end{array}$ & Cassava Dough (Fufu) & $\begin{array}{l}\text { Cassava Flakes } \\
\text { (Garri) }\end{array}$ & $\begin{array}{l}\text { Cassava } \\
\text { Chips } \\
\text { (Abacha) }\end{array}$ \\
\hline & $(N=65)$ & $(N=65)$ & $(N=65)$ & $(N=65)$ \\
\hline 0 & $7.5 \pm 3.18$ & $4.62 \pm 2.76$ & $7.12 \pm 5.79$ & $9.08 \pm 2.40$ \\
\hline 30 & $13.39 \pm 5.96$ & $6.23 \pm 3.95$ & $8.88 \pm 8.21$ & $12.20 \pm 4.23$ \\
\hline 60 & $19.29 \pm 11.37$ & $7.86 \pm 5.62$ & $10.66 \pm 8.98$ & $22.92 \pm 9.83$ \\
\hline 90 & $16.59 \pm 7.76$ & $8.59 \pm 4.78$ & $9.94 \pm 8.49$ & $15.21 \pm 7.33$ \\
\hline 120 & $14.70 \pm 13.09$ & $9.33 \pm 6.27$ & $9.24 \pm 8.05$ & $7.42 \pm 5.96$ \\
\hline
\end{tabular}

Similarly, table 5 shows the mean serum insulin concentration after intake of reference glucose solution, cassava dough (fufu), cassava flakes(garri), cassava flakes (Abacha). Values are expressed as mean + SD.

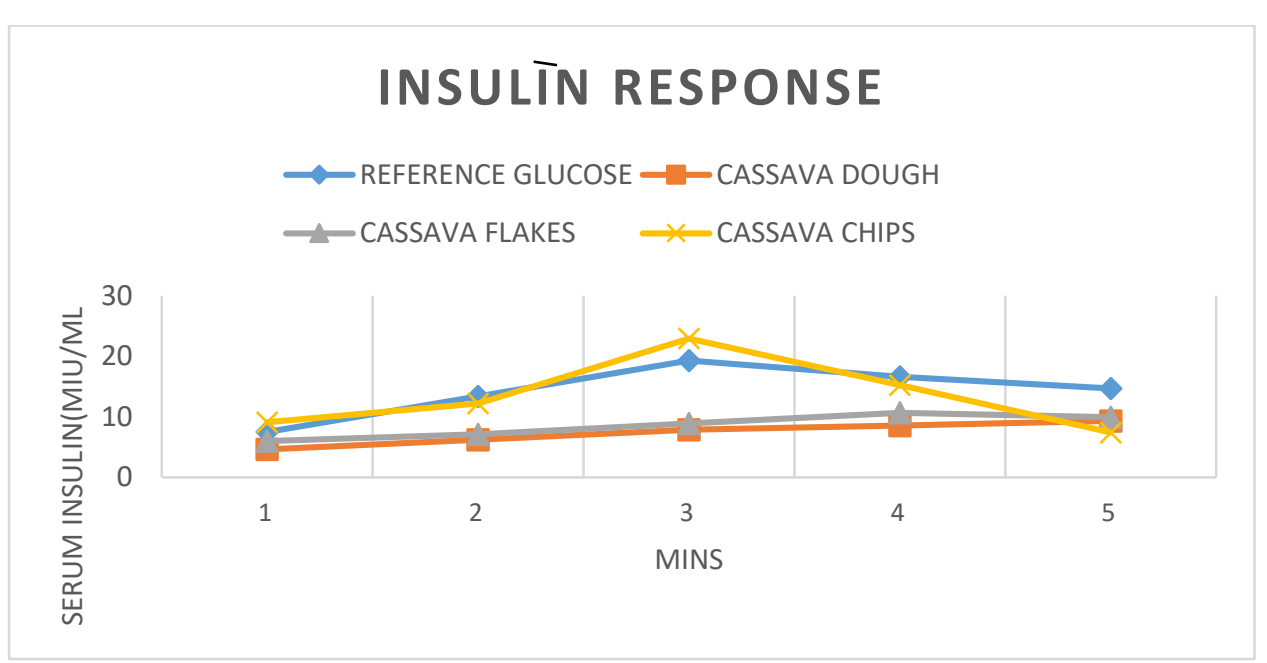

Figure 2: Post-prandial insulin response pattern 
Table 6. Glucose Index (GI), Insulin Index (II), Glyceamic Load (GL), Incremental Glucose Peak Value (IGPV)Glyceamic Profile (GP) And Glyceamic Profile Index (GPI) after intake of cassava dough, flakes, and chips (Mean \pm SD)

\begin{tabular}{lllllll}
\hline MEAL & GI $(\%)$ & II (\%) & GL & IGPV & GP & GPI (\%) \\
\hline $\begin{array}{l}\text { CASSAVA } \\
\text { DOUGH }\end{array}$ & $93.26 \pm 17.31$ & $55.83 \pm 35.47^{\mathrm{bc}}$ & $46.62 \pm 8.66$ & $4.74 \pm 0.98$ & $0.03 \pm 0.01$ & $37.34 \pm 1.16^{\mathrm{bc}}$ \\
\hline $\begin{array}{l}\text { CASSAVA } \\
\text { FLAKES }\end{array}$ & $95.92 \pm 10.34$ & $69.36 \pm 31.03^{\mathrm{ac}}$ & $47.96 \pm 5.18$ & $5.12 \pm 0.95$ & $0.03 \pm 0.01$ & $41.41 \pm 1.60^{\text {ac }}$ \\
\hline CHIPS & $91.94 \pm 27.69$ & $97.02 \pm 20.23^{\mathrm{ab}}$ & $45.97 \pm 13.85$ & $4.74 \pm 0.98$ & $0.03 \pm 0.02$ & $46.19 \pm 2.48^{\mathrm{ab}}$
\end{tabular}

Table 6 indicates the Glycaemic Index (GI), insulin index (II) and glycaemic load (GL) after intake of cassava dough, cassava flakes and chips. Cassava flakes has significantly $(<0.05)$ higher incremental glycaemic peak value, glycaemic index, and glycaemic load but cassava chips had significantly $(<0.05)$ higher insulin index and glycaemic profile index. a=significantly $(p<0.05)$ different from cassava dough $b=$ significantly $(p<0.05)$ different from cassava flakes $c=s i g n i f i c a n t l y ~(p<0.05)$ different from cassava chips

\section{DISCUSSION}

The study showed that the glycaemic index in participants for cassava dough, flakes and chips were $93.26,95.92$ and 91.94 respectively which is high. Overall, a high glycaemic Index was observed in all tested food; therefore, these meals may not be healthy for people that are predisposed to metabolic syndrome when eaten frequently in sizable portions especially those that are inactive. Similar work done by Omoregie and Osagie shows that cassava dough and cassava flakes' glycaemic index was 98.60 and 82.25 while Asinobi et al had the glycaemic index of cassava flakes to be 101.4. $[14,15]$ In another study by Itam et al; the glycaemic indices of cassava flakes were 69.42 while cassava dough 70.54.[16] Glycaemic index of various food differed in values, this may be due to limitations such as variation in the species of cassava products in Nigeria and intra-individual factors which may affect the metabolism of these foods hence may determine the glycaemic Index. Therefore, the glycaemic index of food may have differed from person to person more so the differences in cassava species consumed may have played a significant role. However, the glycaemic index is generally found to be elevated which is like our finding. High glycaemic diet has been associated with increased metabolic disease risk. More so, foods with a high glycaemic index are known to accelerate beta-cell burnout especially in people with insulin deficiency or resistance through glucose toxicity.

The glycaemic load of all the cassava meal studied was found to be significantly increased.

The cassava dough, flakes, and cassava chips' glycaemic load were 46.62, 47.96 and 45.97, respectively. Similarly, Omoregie and Osagie; [14] in their study established that glycaemic load of cassava dough and flakes were 49.30 and 41.1, respectively. This implies that cassava food products have the potential of markedly elevating blood glucose because of its high glycaemic load which may inadvertently increase the demand for insulin on the pancreas which may lead to premature beta cell exhaustion especially in those that have some degree of insulin resistance.

The insulin index of cassava dough, flakes garri and cassava chips were 55.83, 69.36 and 97.02, respectively. Cassava chips insulin index was found to be higher than other food products because food insulin index is dependent not only on carbohydrate content but on fat and protein 
content of a food as well as its interaction quite unlike glycaemic Index which depends only on glucose concentration ${ }^{44}$.Thus, increased the insulin index of cassava chips may be because of increased fat content because frying with oil was the culinary method used in its preparation. This indicates that the cassava meals studied have the propensity to cause post-prandial hyperinsulinemia and may increase demand on $\beta$-cell pancreatic function which may in turn lead to burn out of the $\beta$-cell of the pancreas.

Despite the increased raised glycaemic index and insulin index, glycaemic profile index of the food is reduced, indicating that the cassava meal does not cause significantly prolonged postprandrial hyperglycaemia in healthy people.

\section{CONCLUSION}

Glycaemic index, Insulin Index and glycaemic load of cassava dough, flakes and chips were found to be high; however, glycaemic profile index of all the cassava meals were not increased. Cassava chips was highly insulinogenic than other cassava food products. Cassava dough, flakes and chips as suggested by this study has the potential to worsen the dysglycaemia in people that have tendency to develop metabolic syndrome depending on frequency of intake and activity.

Recommendation: Fufu, garri and cassava chips; should be eaten with caution especially among overweight, obese, diabetic, and inactive people as

\section{REFERENCES}

1. Jia-Yu Zhang, Yu-Ting Jiang, Ya-Shu Liu, Qing Chang YHZ\& Q-JW. The association between glycemic index, glycemic load, and metabolic syndrome: a systematic review and dose-response meta-analysis of observational studies. Eur J Nutr. 2019; 59:451-463.

2. Liu S, Manson JE, Buring JE, Stampfer MJ, Willett WC, it has the potential to precipitate or worsen dysglycaemia. Insulin index of cassava chips using other culinary method can be compared with method used in this study.

List of abbreviations: II: Insulin Index, GP: glycaemic profile, GL: glycaemic load, GI: glycaemic Index, IGPV: Incremental glucose peak value, GPI: glycaemic profile index, DII: Dietary Insulin Index, DM: Diabetes Mellitus, has-CRP: High Sensitivity CReactive Protein, HDL-c: High Density Lipoprotein Cholesterol, Conc: concentration, t: time, BMI: Body Mass Index.

Funding: The authors declare everything was selffunded.

Competing Interests: We declare that we have no competing interest that may have inappropriately influenced this study.

Authors contributions: This work was a collaborative study among all authors. Author B.K.M originated the concept and designed the study; defined the intellectual content; performed the literature search; participated in clinical studies; data acquisition, analysis, and manuscript preparation. Authors S.A.A; B.B; T.T.G participated in designing of the study, clinical studies, statistical analysis, and manuscript preparation and critical review.

Ridker PM. Relation between a diet with a high glycemic load and plasma concentrations of highsensitivity C-reactive protein in middle-aged women. Am J Clin Nutr. 2002; 75(3):492-498

3. Ford ES, Liu S. Glycemic index and serum high-density lipoprotein cholesterol concentration among US adults. Arch Intern Med. 2001;161(4):572-576. 
4. Liu S, Manson JE, Stampfer MJ, Holmes MD, Hu FB, Hankinson SE, et al. Dietary glycemic load assessed by food-frequency questionnaire in relation to plasma high-density-lipoprotein cholesterol and fasting plasma triacylglycerols in postmenopausal women. $\mathrm{Am}$ J Clin Nutr. 2001;73(3):560-566.

5. Araoye MO. Research Methodology with Statistics for Health and Social Sciences. Ilorin; Nathadex publishers. 2004.115-129

6. FAO/WHO. Diet, Nutrition, and the Prevention of Chronic Diseases (Report of a joint WHO and FAO Expert Consulation). WHO Tech Rep Ser [Internet]. 2003;916. Available from: https://apps.who.int/iris/bitstream/handle/10665/42 665/WHO_TRS_916.pdf?sequence=1

7. Stadlmayr.B, Charrondiere U.R, Enujiugha V.N, Bayili R.G, Fagbohoun E.G, Samb.B Table de composition des aliments d'Afrique de l'Ouest West African Food Composition Table. Food and Agriculture Organization of the United Nations; Rome, Italy. 2012:1-171

8. Howard Rasmussen, Kathleen C Zawalich, Shridar Ganesan, Roberto Calle WSZ. Physiology and Pathophysiology of Insulin Secretion. Am Diabetes Assoc. 1990;13(6):655-666.

9. Yeh ST. Using a trapezoidal rule for the area under a curve calculation-SAS advanced tutorial. In Proceedings of the 27th Annual Conference of SAS Users Group International 2002 Apr: 14-17.

10. Faraggi $D$, Reiser $B$. Estimation of the area under the ROC curve. Statistics in medicine. 2002 ;21(20):30933106.f'g, erg,', r,g.

11. Brouns, F; Bjorck, I; Frayn K.I; Gibbs A. Glycaemic index methodology. Nutr Res Rev. 2005;18(1):145-171.

12. Rosén LA, Silva LO, Andersson UK, Holm C, Östman EM, Björck IM. Endosperm and whole grain rye breads are characterized by low post-prandial insulin response and a beneficial blood glucose profile. Nutrition. 2009; $1: 8(1): 42$

13. Helrich K. Official Methods of Analysis of AOAC International. In: Association of Official Analysis Chemists International. 1990. 5th Edition.AOAC Inc. Arlington USA.22:56 - 58.

14. Omoregie ES, Osagie AU. Glycemic indices and glycemic load of some Nigerian foods. Pakistan J Nutr. 2008;7(5):710-716.

15. Asinobi C, Uzoagba H, Mba-Anyadioha A, John
Kennedy N. Glycemic index of some traditional fortified staple meals on the postprandial blood glucose responses of Nigerian undergraduate students: an open-label study. FFHD.2016;6(7):414424.

16. Itam E H, Itam A H, O OM, Ejemot-Nwadiaro R, Asenye $\mathrm{M} E$, Ezike N. Effect of processing method on the glycemic index of some carbohydrate staples (Manihot esculanta, Ipomoea batata and Dioscorea rotundata) in both normal and diabetic subjects. Sch Res Libr Ann Biol Res. 2012;3(12):5507-5510. 